\title{
Cardiorespiratory Fitness
}

National Cancer Institute

\section{Source}

National Cancer Institute. Cardiorespiratory Fitness. NCI Thesaurus. Code C88164.

The ability of the heart and lungs to deliver blood and oxygen to the tissues during aerobic activity. It is a general measure of the relative conditioning of the heart and respiratory system. 